Case Study

\title{
Effect of joint mobilization and stretching on respiratory function and spinal movement in very severe COPD with thoracic kyphosis
}

\author{
JOONG-SAN WANG, PT, PhD ${ }^{1)}$ \\ 1) Department of Physical Therapy, Yeoju Institute of Technology: 338 Sejong-ro, Yeoju-si, \\ Gyeonggi-do, Republic of Korea
}

\begin{abstract}
Purpose] The purpose of this study was to analyze the effect of joint mobilization and stretching of the thoracic cage for very severe chronic obstructive pulmonary disease (COPD) on a patient with thoracic kyphosis. [Subject and Methods] The subject is a 73-year-old female COPD patient with thoracic kyphosis. The intervention methods were comprised of joint mobilization and stretching. The program consisted of 30 minute sessions three days per week for eight weeks. Respiratory function, spinal curve, and spinal movement (thoracic and lumbar spine) were measured. [Results] Joint mobilization and stretching did not result in noticeable changes in the respiratory function of the patient; however, positive changes were observed, including decreased thoracic kyphosis curve, increased lumbar lordosis curve, and increased spinal movement. [Conclusion] The results of the analysis show that the patient's age, body mass index, duration of the disease, COPD level, and posture should be considered in the clinical decision to perform pulmonary physical therapy for patients with complicated diseases such as COPD with thoracic kyphosis.

Key words: COPD, Joint mobilization, Stretching
\end{abstract}

(This article was submitted Jun. 16, 2015, and was accepted Jul. 9, 2015)

\section{INTRODUCTION}

Chronic obstructive pulmonary disease (COPD) is characterized by airflow limitation, and its symptoms include dyspnea, cough, and sputum ${ }^{1,2)}$. Its diagnosis requires a spirometry, COPD may be diagnosed when the ratio of forced expiratory volume in one second over forced vital capacity $\left(\mathrm{FEV}_{1} / \mathrm{FVC}\right) \leq 70 \%{ }^{1}$. Due to physiological deterioration, elderly people experience weakened respiratory function, stiffness in the joints and connective tissues of the rib cage, and increased thoracic kyphosis ${ }^{3-5}$. COPD leads to decreased force strength and endurance of the respiratory muscles, as well as deteriorated gait ability6); thoracic kyphosis causes severity of flexed posture, geriatric depression, muscular impairment, and gait impairment in elderly people ${ }^{7)}$. Accordingly, when an elderly person has thoracic kyphosis with COPD, the consequent damages, combined with signs of aging, can negatively affect the entire body.

Alignment of the skeletal system in the chest, aling with chest wall compliance, are related to respiratory function ${ }^{8,9)}$, while thoracic kyphosis and consequent changes in the rib cage lead to decreased lung capacity ${ }^{10)}$. Specialized pul-

Corresponding author. Joong-San Wang (E-mail: king9655@ empas.com)

C2015 The Society of Physical Therapy Science. Published by IPEC Inc. This is an open-access article distributed under the terms of the Creative Commons Attribution Non-Commercial No Derivatives (by-ncnd) License $<$ http://creativecommons.org/licenses/by-nc-nd/3.0/>. monary physical therapy should be explored to address the combined problems of thoracic kyphosis with COPD. Earlier studies have shown that joint mobilization and stretching of the thoracic spine can be very effective for reducing pain and improving mobility, range of motion, posture, and respiratory function ${ }^{11-14)}$. However, there are few studies that have examined the effect of joint mobilization and stretching via orthopedic manual therapy on respiratory function, spinal curve, and spinal movement of elderly people with thoracic kyphosis and very severe COPD.

This research conducted a case study of an elderly COPD patient with thoracic kyphosis to examine the effect of joint mobilization and stretching of the thoracic cage on respiratory function, spinal curve, and spinal movement.

\section{SUBJECT AND METHODS}

The subject of the case study is a 73-year-old female. She is $1.56 \mathrm{~m}$ in height, $42 \mathrm{~kg}$ in weight (underweight) with BMI of $17.25 \mathrm{~kg} / \mathrm{m}^{2}$. She was diagnosed with unspecified COPD in 2001 at a division of pulmonology based on the results of her computer tomography (CT) scan and spirometry. Currently, she is receiving regular medical treatment. Her thoracic curve was measured with Spinal Mouse ${ }^{\circledR}$ (Idag, Swiss), and the results confirmed thoracic kyphosis $\left(50.5 \pm 0.7^{\circ}\right)$. A spirometer (Fitmate MED, Italy) was used to measure her respiratory function, and the result indicated very severe $\mathrm{COPD}$ with $\mathrm{FEV}_{1} / \mathrm{FVC}<70 \%$ and FEV1 predicted $30 \%{ }^{1)}$. She scored a 28 on the Korean version of the mini-mental state exam, indicating normal cognitive function ${ }^{15}$. She 
3330 J. Phys. Ther. Sci. Vol. 27, No. 10, 2015

Table 1. Changes of respiratory function, spinal curve and spinal movement

\begin{tabular}{|c|c|c|c|c|c|c|}
\hline Variable & & & Pre & 4 weeks & 8 weeks & 8 weeks - Pre \\
\hline \multirow{3}{*}{$\begin{array}{l}\text { Respiratory } \\
\text { function }\end{array}$} & \multicolumn{2}{|c|}{ FVC (\% predicted) } & $57.5 \pm 3.5$ & $50.5 \pm 13.4$ & $58.0 \pm 1.4$ & $0.5 \pm 4.9$ \\
\hline & \multicolumn{2}{|c|}{$\mathrm{FEV}_{1}(\%$ predicted $)$} & $24.5 \pm 2.1$ & $23.5 \pm 3.5$ & $25.5 \pm 0.7$ & $1.0 \pm 1.4$ \\
\hline & \multicolumn{2}{|c|}{$\mathrm{FEV}_{1} / \mathrm{FVC}(\%)$} & $47.5 \pm 0.7$ & $52.0 \pm 5.6$ & $48.0 \pm 1.4$ & $0.5 \pm 0.7$ \\
\hline \multirow{2}{*}{$\begin{array}{l}\text { Spinal } \\
\text { curve }\end{array}$} & \multicolumn{2}{|c|}{ Thoracic $\left(^{\circ}\right)$} & $50.5 \pm 0.7$ & $46.0 \pm 1.4$ & $45.5 \pm 0.7$ & $-5.0 \pm 1.4$ \\
\hline & \multicolumn{2}{|l|}{ Lumbar $\left(^{\circ}\right)$} & $-3.5 \pm 0.7$ & $-6.5 \pm 0.7$ & $-8.0 \pm 1.4$ & $-4.5 \pm 2.1$ \\
\hline \multirow{4}{*}{$\begin{array}{l}\text { Spinal } \\
\text { movement }\end{array}$} & \multirow{2}{*}{ Thoracic $\left({ }^{\circ}\right)$} & Flexion & $7.5 \pm 3.5$ & $10.5 \pm 3.5$ & $12.0 \pm 0.0$ & $4.5 \pm 3.5$ \\
\hline & & Extension & $-5.0 \pm 1.4$ & $-6.0 \pm 1.4$ & $-8.0 \pm 0.0$ & $-3.0 \pm 1.4$ \\
\hline & \multirow{2}{*}{ Lumbar $\left(^{\circ}\right)$} & Flexion & $14.0 \pm 1.4$ & $15.5 \pm 0.7$ & $17.5 \pm 0.7$ & $3.5 \pm 2.1$ \\
\hline & & Extension & $-6.0 \pm 0.0$ & $-8.5 \pm 0.7$ & $-8.5 \pm 0.7$ & $-2.5 \pm 0.7$ \\
\hline
\end{tabular}

Values are means $\pm \mathrm{SD}$

$\mathrm{FEV}_{1}$ : forced expiratory volume in 1 second, $\mathrm{FVC}$ : forced vital capacity

could walk alone, and had no history of surgical operations in the vertebral region. The local ethics committee of the Namseoul University of Cheonan, South Korea approved the protocol for this study (NSU-140929-2). This case study was conducted by subjects that informed consent was obtained.

The patient went through a total of 24 sessions of 30 minute intervention three times per week for eight weeks between September and November 2014. The intervention method included joint mobilization using KaltenbornEvjenth orthopedic manual therapy (KEOMT) and Evjenth and Hamberg stretching (EH stretching $)^{12-14)}$. All treatment was applied by a therapist who had completed a KEOMT spine advance course.

For joint mobilization, thoracic segmental mobilization (traction with extension) and specific rib mobilization (ventral) were applied ${ }^{14)}$. Joint mobilization was applied at the intensity of sliding grade III ${ }^{16)}$ - without discomfort to the patient-within anatomic range of the joint for 7-10 seconds ${ }^{14}$. Stretching was applied to the rectus abdominalis muscle, sternocleidomastoid muscles, and pectoralis major muscles. The stretching technique began with 5 seconds of isometric contraction of the muscle, followed by $2-3$ seconds of relaxation; then, the therapist slowly moved the patient into the posture of passive stretching ${ }^{12,13)}$, which was held for 18 seconds. Then, 5 seconds of isometric contraction of the antagonist muscle was applied, followed by 10 seconds of relaxation.

To examine the effect of the intervention, the patient's respiratory function, spinal curve, and spinal movement were measured. To assess respiratory function, a spirometer was used to gauge FVC, $\mathrm{FEV}_{1}$, and $\mathrm{FEV}_{1} / \mathrm{FVC}$. Spinal curve and movement were measured with Spinal Mouse ${ }^{\circledR 17)}$. This device has a high level of credibility in terms of correlation coefficients and intra-class coefficients for flexion and extension $^{18)}$.

All measurements were done three times: before intervention, at 4 week, and at 8 week. Each item was measured twice, and the average both measurements was used. All of the data was codified and analyzed with SPSS WIN (ver. 21 ), to determine the average and standard deviations.

\section{RESULTS}

The patient's respiratory function did not change noticeably when measured before the intervention and after 8 weeks of intervention, even though her $\mathrm{FVC}, \mathrm{FEV}_{1}$, and $\mathrm{FEV}_{1} / \mathrm{FVC}$ increased slightly. As for spinal curve and movement, her thoracic kyphosis curve decreased, whereas her lumbar lordosis curve and spinal movement gradually increased as the intervention progressed. The changes between before the intervention and after 8 weeks of intervention were as follows: thoracic kyphosis curve $-5.0 \pm 1.4^{\circ}$, lumbar lordosis curve $-4.5 \pm 2.1^{\circ}$, thoracic flexion $4.5 \pm 3.5^{\circ}$, thoracic extension $-3.0 \pm 1.4^{\circ}$, lumbar flexion $3.5 \pm 2.1^{\circ}$, and lumbar extension $-2.5 \pm 0.7^{\circ}$. These indicate positive changes in the patient's spinal curve and movement (Table 1).

\section{DISCUSSION}

In this study, a case study was conducted to examine the effect of thoracic cage of joint mobilization and EH stretching of the thoracic cage on respiratory function, spinal curve, and spinal movement for a single COPD patient with thoracic kyphosis. The patient's respiratory function $\left(\mathrm{FVC}, \mathrm{FEV}_{1}\right.$, $\mathrm{FEV}_{1} / \mathrm{FVC}$ ) did not change noticeably. Putt et al. ${ }^{19)}$ reported that application of a hold-relax technique to the pectoralis major muscle of COPD patients resulted in increased lung capacity, which was not consistent with our research outcomes. We view that the patient's respiratory function did not change noticeably because of her advanced age, thoracic kyphosis, the long duration of her disease (over 10 years), and her underweight condition in terms of BMI. Celedon et al. ${ }^{20)}$ reported that being underweight was associated with asthma and symptomatic airway hyperresponsiveness in females; thus, her underweight status could have significantly affected the outcomes of our research. Respiratory muscle strength exercise or electrical stimulation is recommended, since respiratory function is related to weakenss of the respiratory muscles in patients with $\mathrm{COPD}^{21,22)}$. However, our research outcomes provided important information: the patient's age, BMI, duration of the disease, COPD level, and posture should be considered in the clinical decision making onto perform pulmonary physical therapy on for COPD patients. 
Meanwhile, positive changes were observed in the patient's spinal curve and movement as the intervention progressed. Between before the intervention and after 8 weeks of intervention, the patient's thoracic and lumbar curves both improved in a standing posture. Also, we found that joint mobilization and stretching of the thoracic cage had a positive effect on lumbar curve and movement.

Bautmans et al. ${ }^{23)}$ found that after three months of joint mobilization, the angle of the thoracic curve of an elderly female with osteoporosis and thoracic kyphosis decreased from $52.5 \pm 2.2^{\circ}$ to $49.1 \pm 2.0^{\circ}$, and her posture improved markedly, which is consistent with the findings of our research. As thoracic kyphosis grows more severe, spine extensor muscles weaken ${ }^{7}$; thus, stretching and extensor muscles exercise is necessary ${ }^{24)}$. EH stretching was used in this study, which involves hold-relax of the agonist muscle followed by contraction of the antagonist muscle. This stretches the flexor muscles of the front part of the trunk that had been shortened due to a distorted posture; it also strengthens extensor muscles on the back part of trunk, which resulted in decreased thoracic kyphosis and increased spinal movement. Similarly, Etnyre and Abraham ${ }^{25)}$ compared the effects of static stretching, contract-relax stretching, and contract-relax-antagonist-contract stretching; they argued that the last method was the most effective for improving the range of motion of the joint.

The limitation of our research is that the case study only involved one elderly COPD patient with thoracic kyphosis, which makes it difficult to apply the results more broadly.

Although the study results showed that joint mobilization and stretching of the thoracic cage had little effect on improving respiratory function of very severe COPD patients with thoracic kyphosis, the same intervention could be effective in improving patients' spinal curve and movement Thus, the patient's age, BMI, duration of the disease, COPD level, and posture should be considered in clinical decision making on pulmonary physical therapy for very severe COPD patients with thoracic kyphosis. Lastly, future research could examine physical therapies that improve both respiratory function and spinal curve and movement for COPD patients with thoracic kyphosis.

\section{REFERENCES}

1) Celli BR, MacNee W, Agusti A, et al. ATS/ERS Task Force: Standards for the diagnosis and treatment of patients with COPD: a summary of the ATS/ ERS position paper. Eur Respir J, 2004, 23: 932-946. [Medline] [CrossRef]

2) Jette DU, Bourgeois MC, Buchbinder R: Pulmonary rehabilitation following acute exacerbation of chronic obstructive pulmonary disease. Phys Ther, 2010, 90: 9-12. [Medline] [CrossRef]

3) Lalley PM: The aging respiratory system - pulmonary structure, function and neural control. Respir Physiol Neurobiol, 2013, 187: 199-210. [Medline] [CrossRef]
4) Neumann DA: Kinesiology of the musculoskeletal system (Foundations for rehabilitation). St Louis: Mosby, 2010.

5) Hinman MR: Comparison of thoracic kyphosis and postural stiffness in younger and older women. Spine J, 2004, 4: 413-417. [Medline] [CrossRef]

6) Roig M, Eng JJ, MacIntyre DL, et al.: Associations of the Stair Climb Power Test with muscle strength and functional performance in people with chronic obstructive pulmonary disease: a cross-sectional study. Phys Ther, 2010, 90: 1774-1782. [Medline] [CrossRef]

7) Balzini L, Vannucchi L, Benvenuti F, et al.: Clinical characteristics of flexed posture in elderly women. J Am Geriatr Soc, 2003, 51: 1419-1426. [Medline] [CrossRef]

8) Dyer CA, Stockley RA: The aging lung. Rev Clin Gerontol, 2006, 16: 99-111. [CrossRef]

9) Penafortes JT, Guimarães FS, Moço VJ, et al.: Association among posture, lung function and functional capacity in cystic fibrosis. Rev Port Pneumol, 2013, 19: 1-6. [Medline] [CrossRef]

10) Culham EG, Jimenez HA, King CE: Thoracic kyphosis, rib mobility, and lung volumes in normal women and women with osteoporosis. Spine, 1994, 19: 1250-1255. [Medline] [CrossRef]

11) Ko TS, Joung HB, Kim JA: The effects of thoracic mobilization in pain, disability index and spinal mobility in chronic back pain patients. J Spec Edu Rehabil Sci, 2009, 48: 115-137.

12) Evjenth O, Hamberg J: Muscle stretching in manual therapy: A clinical manual, Vol. 1. Sweden: Alfta Rehab, 2001.

13) Evjenth O, Hamberg J: Muscle stretching in manual therapy: A clinical manual, Vol. 2. Sweden: Alfta Rehab, 2001.

14) Kaltenborn FM: The spine: Basic evaluation and mobilization techniques, 3rd ed. Norli, 1993.

15) Kwon YC, Park JH: Korean version of Mini-Mental State Examination (MMSE) Part I: development of the test for the eldery. J Korean Neuropsychiatr Assoc, 1989, 28: 125-135.

16) Gallego PH, Moreno JM, López OL, et al.: Indirect influence of specific Kaltenborn glide mobilizations of the carpal joint on a subject with neurological impairments. J Bodyw Mov Ther, 2007, 11: 275-284. [CrossRef]

17) Mannion AF, Knecht $K$, Balaban G, et al.: A new skin-surface device for measuring the curvature and global and segmental ranges of motion of the spine: reliability of measurements and comparison with data reviewed from the literature. Eur Spine J, 2004, 13: 122-136. [Medline] [CrossRef]

18) Post RB, Leferink VJ: Spinal mobility: sagittal range of motion measured with the SpinalMouse, a new non-invasive device. Arch Orthop Trauma Surg, 2004, 124: 187-192. [Medline] [CrossRef]

19) Putt MT, Watson M, Seale H, et al.: Muscle stretching technique increases vital capacity and range of motion in patients with chronic obstructive pulmonary disease. Arch Phys Med Rehabil, 2008, 89: 1103-1107. [Medline] [CrossRef]

20) Celedón JC, Palmer LJ, Litonjua AA, et al.: Body mass index and asthma in adults in families of subjects with asthma in Anqing, China. Am J Respir Crit Care Med, 2001, 164: 1835-1840. [Medline] [CrossRef]

21) Kaneko H, Maruyama H, Sato H: Relationship between expiratory activity of the lateral abdominal muscle and exercise tolerance in chronic obstructive pulmonary disease. J Phys Ther Sci, 2008, 20: 147-151. [CrossRef]

22) Ito K, Nozoe T, Okuda M, et al.: Electrically stimulated ventilation feedback improves the ventilation pattern in patients with COPD. J Phys Ther Sci, 2015, 27: 325-330. [Medline] [CrossRef]

23) Bautmans I, Van Arken J, Van Mackelenberg M, et al.: Rehabilitation using manual mobilization for thoracic kyphosis in elderly postmenopausal patients with osteoporosis. J Rehabil Med, 2010, 42: 129-135. [Medline] [CrossRef]

24) Yoo WG: Effect of thoracic stretching, thoracic extension exercise and exercises for cervical and scapular posture on thoracic kyphosis angle and upper thoracic pain. J Phys Ther Sci, 2013, 25: 1509-1510. [Medline] [CrossRef]

25) Etnyre BR, Abraham LD: Gains in range of ankle dorsiflexion using three popular stretching techniques. Am J Phys Med, 1986, 65: 189-196. [Medline] 